\title{
MIF promoter polymorphism increases peripheral blood expression levels, contributing to increased susceptibility and poor prognosis in hepatocellular carcinoma
}

\author{
LIFENG QIN $^{1}$, JINMEI QIN ${ }^{2}$, XIAOPING LV ${ }^{3}$, CAIQIAO YIN ${ }^{1}$, \\ QIAN'E ZHANG ${ }^{1}$ and JIQIAO ZHANG ${ }^{1}$ \\ ${ }^{1}$ Department of Gastroenterology, Minda Hospital of Hubei Minzu University, Enshi, Hubei 445000; \\ Departments of ${ }^{2}$ Infectious Diseases and ${ }^{3}$ Gastroenterology, The First Affiliated Hospital \\ of Guangxi Medical University, Nanning, Guangxi 530021, P.R. China
}

Received December 17, 2020; Accepted April 28, 2021

DOI: $10.3892 / \mathrm{ol} .2021 .12810$

\begin{abstract}
Hepatocellular carcinoma (HCC) is one of the most common malignancies in the world. The etiology and pathogenesis of HCC remain unclear. Macrophage migration inhibitory factor (MIF) plays a critical role in the pathogenesis of hepatocellular carcinoma. The association between MIF polymorphisms and its expression level in HCC has rarely been demonstrated. In the present study, the peripheral blood of 202 patients with HCC (HCC group), 242 patients with chronic hepatitis B (CHB group), 215 patients with liver cirrhosis (LC group) and 227 healthy volunteers (normal group) were collected, DNA was extracted and the target fragment of MIF gene was amplified using PCR. The products were then sequenced, and the expression levels of MIF protein were tested using ELISA. The results showed that the MIF rs755622 polymorphism was associated with an increased susceptibility and metastasis of $\mathrm{HCC}$, and that the genotypes GC and CC were associated with poor prognosis of HCC. Compared with the normal, CHB and LC groups, the expression of MIF in the peripheral blood of the HCC group was significantly increased, and the high expression was associated with to poor prognosis. In the HCC group, MIF protein levels for genotypes GC and CC were increased compared with those of genotype GG. The current study indicated that the MIF rs755622 polymorphism is associated with susceptibility and metastasis of HCC, and that the GC and CC genotypes may be indicators of poor prognosis, which may be ascribed
\end{abstract}

Correspondence to: Professor Jiqiao Zhang or Professor Qian'e Zhang, Department of Gastroenterology, Minda Hospital of Hubei Minzu University, 2 Wufengshan Road, Enshi, Hubei 445000, P.R. China

E-mail: zhangjiqiao1983@163.com

E-mail: zhangqiane1977@163.com

Key words: macrophage migration inhibitory factor, hepatocellular carcinoma, single nucleotide polymorphism to the MIF rs755622 polymorphism leading to elevated MIF protein expression in peripheral blood.

\section{Introduction}

Hepatocellular carcinoma (HCC), one of the most common malignancies in the world (1). According to statistics, there are $\sim 700,000$ new cases in the world every year, and Chinese patients account for as much as $54 \%$ of these cases (2). It develops mostly on the basis of viral hepatitis and cirrhosis, which is characterized by insidious onset, poor prognosis and the large consumption of medical resources (1). The etiology and pathogenesis of HCC are not completely clear, and it is considered to be associated with the hepatitis virus, contaminated food and water, poisons, parasites and genetic factors (1). Importantly, genetic factors are an important basis of HCC. Studies have confirmed that single nucleotide polymorphisms (SNPs) located in promoter regions and coding regions of critical genes can affect susceptibility to $\operatorname{HCC}(3,4)$.

Macrophage migration inhibitory factor (MIF), a cytokine with multiple biological activities, plays an important regulatory role in the endocrine-immune network of the human body. It can inhibit the migration of macrophages and promote the accumulation, proliferation, activation and secretion of macrophages at the site of inflammation, thus playing a critical role in the pathogenesis of diseases such as inflammation, autoimmune diseases and tumors (5). The gene encoding MIF in humans is located on the long arm of chromosome 22 (22q11.2), covering a length of $1 \mathrm{~kb}$. There are several polymorphic loci in the MIF gene. In previous years, numerous studies $(6,7)$ have found that polymorphisms in the MIF gene and the expression levels of MIF are closely associated with the susceptibility, progression, prognosis and drug resistance of a number of diseases, for example, sepsis, autoimmune diseases, cancer, metabolic disorders such as type 2 diabetes and obesity.

To date, the association between MIF polymorphisms and their expression levels in HCC has rarely been demonstrated. The present study aimed to analyze the association of MIF gene SNPs with HCC and detected MIF protein expression levels in peripheral blood from patients with HCC in the 
Chinese Han population (Fig. 1). Since most HCC cases are due to hepatitis and cirrhosis, patients with chronic hepatitis B (CHB) and liver cirrhosis (LC) were used as controls.

Currently, HCC is a refractory disease, the present study will help to explore new predictive/prognostic indicators and therapeutic targets for HCC.

\section{Materials and methods}

Patients and controls. From February 2014 to January 2018, 886 participants were enrolled in the First Affiliated Hospital of Guangxi Medical University, including 202 patients with HCC (HCC group), 242 patients with CHB (CHB group), 215 patients with LC (LC group) and 227 healthy volunteers (normal group). Inclusion criteria included: i) Patients living in China in the long-term, ii) the last three generations of immediate family members being Han, with no marriages to individuals of other nationalities and iii) patients with HCC, CHB and LC meeting the relative diagnosis norms and guidelines (8-10). Exclusion criteria included: i) Participants with other neoplastic diseases or hepatic diseases and ii) participants with genetic relationships to each other. Tumor, node and metastasis (TNM) staging was judged according to the Barcelona Clinic Liver Cancer strategy (11). All patients with HCC underwent $\alpha$-fetoprotein (AFP) testing and imaging examinations (CT and MRI). Image classification (including lump type, nodular type and diffuse type) was carried out through imaging examination (12) and the presence or absence of lymph node metastasis and distant metastasis was determined by independent pathologists and imaging experts in the First Affiliated Hospital of Guangxi Medical University (Nanning, China) according to the Diagnosis and staging of hepatocellular carcinoma (HCC): Current guidelines (12).

Written informed consent was obtained from all participants. The Ethics Committee of The First Affiliated Hospital of Guangxi Medical University approved the study (approval no. 2014-KY-E-049). The privacy of all participants was protected consistently.

DNA extraction, PCR and genotyping. In total, $4 \mathrm{ml}$ of peripheral blood was collected from the median elbow vein of every participant and stored at $-80^{\circ} \mathrm{C}$. DNA was extracted using the Genomic DNA Extraction kit (Tiangen Biotechnology Co., Ltd.) according to the manufacturer's instructions (centrifugal column method). DNA was added to 50-100 $\mu \mathrm{l}$ Tris-ethylenediamine tetraacetic acid buffer (TE) for rehydration, and the concentration and purity of DNA was assessed before storage at $-80^{\circ} \mathrm{C}$.

The primers used to amplify the MIF gene (the sequences included rs755622, rs1007888 and rs2096525) were designed and synthesized by Takara Biotechnology Co., Ltd. The sequences were as follows: MIF rs755622 Forward: 5'-GGCGACTAA CATCGGTGA-3' and reverse: 5'-GCAGAAGGACCAGGA GAC-3', MIF rs1007888 forward: 5'-TTAGGGAGGGGTAAG AAC-3' and reverse: 5'-GAAGCCCATGTAAAAGAA-3', MIF rs2096525 forward: 5'-GGTGCCCACCGGACGAGGGAT-3' and reverse: 5'-GTCGGGCCCCGAACGTCCACT-3'.

PCR reactions were performed in a thermocycler (Veriti; Applied Biosystems; Thermo Fisher Scientific, Inc.). The total reaction system was $20 \mu \mathrm{l}$, including $1 \mu \mathrm{l}$ genomic DNA, $1 \mu \mathrm{l}$ Tks Gflex DNA polymerase, $0.5 \mu 1$ forward primer, $0.5 \mu 1$ reverse primer, $10 \mu \mathrm{l} 2 \mathrm{X}$ Gflex PCR buffer and up to $20 \mu \mathrm{l}$ with double-distilled water. PCRs for MIF rs755622 were performed under the following conditions: Initial denaturation at $95^{\circ} \mathrm{C}$ for $3 \mathrm{~min}$, followed by amplification for three cycles (denaturation at $95^{\circ} \mathrm{C}$ for $30 \mathrm{sec}$, annealing at $60^{\circ} \mathrm{C}$ for $30 \mathrm{sec}$ and extension at $72^{\circ} \mathrm{C}$ for $30 \mathrm{sec}$ ), followed by three cycles (denaturing at $95^{\circ} \mathrm{C}$ for $30 \mathrm{sec}$, annealing at $58^{\circ} \mathrm{C}$ for $30 \mathrm{sec}$ and extension at $72^{\circ} \mathrm{C}$ for $30 \mathrm{sec}$ ), followed by 25 cycles (denaturing at $95^{\circ} \mathrm{C}$ for $30 \mathrm{sec}$, annealing at $55^{\circ} \mathrm{C}$ for $30 \mathrm{sec}$ and extension at $72^{\circ} \mathrm{C}$ for $30 \mathrm{sec}$ ), followed by five cycles (denaturing at $95^{\circ} \mathrm{C}$ for $30 \mathrm{sec}$, annealing at $53^{\circ} \mathrm{C}$ for $30 \mathrm{sec}$ and extension at $72^{\circ} \mathrm{C}$ for $30 \mathrm{sec}$ ) with a final extension at $72^{\circ} \mathrm{C}$ for $7 \mathrm{~min}$. The PCR for MIF rs1007888 was performed under the following conditions: Initial denaturation at $95^{\circ} \mathrm{C}$ for $4 \mathrm{~min}$, followed by amplification for 35 cycles (denaturation at $94^{\circ} \mathrm{C}$ for $30 \mathrm{sec}$, annealing at $55^{\circ} \mathrm{C}$ for $30 \mathrm{sec}$ and extension at $72^{\circ} \mathrm{C}$ for $30 \mathrm{sec}$ ) and a final extension at $72^{\circ} \mathrm{C}$ for $7 \mathrm{~min}$. PCR for MIF rs2096525 was performed under the following conditions: Initial denaturation at $95^{\circ} \mathrm{C}$ for $5 \mathrm{~min}$, followed by amplification for 40 cycles (denaturation at $95^{\circ} \mathrm{C}$ for $30 \mathrm{sec}$, annealing at $65^{\circ} \mathrm{C}$ for $30 \mathrm{sec}$ and extension at $72^{\circ} \mathrm{C}$ for $30 \mathrm{sec}$ ) with a final extension at $72^{\circ} \mathrm{C}$ for $7 \mathrm{~min}$.

To confirm the genotypes for each sample, PCR products with forward primers were sent to GenScript Biotechnology Co., Ltd. for DNA sequencing. The sequencer used was an Applied Biosystems 3730xl DNA Analyzer (Thermo Fisher Scientific, Inc.).

Protein expression of MIF detection via ELISA. The expression levels of MIF protein in the peripheral blood from all participants were tested with Human MIF ELISA kits (cat. no. EK0813; Boster Biological Technology Co., Ltd.). The specific method of ELISA followed the manufacturer's instructions. Assays were performed in triplicate for each sample. With $50 \%$ of the maximum MIF concentration as the cut-off point, patients with HCC with survival information were divided into the high expression group and the low expression group for subsequent survival analysis.

Patient follow-up. Clinical follow-up after diagnosis was performed every 3 months during the first two years, and then every 6 months until the patient died. The content of the follow-up included asking about the patient's symptoms, physical examination, testing of AFP, CT or MRI of the upper abdomen. Liver function, HBV-DNA, or HCV-RNA tests were performed when necessary. Telephone follow-up was performed when the patients did not come to the hospital for follow-up visits on time.

Statistical analysis. Normally distributed measurement data were represented as mean $\pm \mathrm{SD}$. The Hardy-Weinberg equilibrium was evaluated with the Haploview 4.2 software (Broad Institute). The minimum sample size and statistical power were calculated by the PASS 11 software (NCSS, Inc.). Allele and genotype frequencies were compared between the groups using the Pearson's $\chi^{2}$ test and Bonferroni's correction. The measurement data of multiple groups were compared with each other using one-way and two-way ANOVA and post hoc Bonferroni's correction. Overall survival time (from diagnosis to the last follow-up or death) was analyzed using the Kaplan-Meier method and compared using the log-rank test. $\mathrm{P}<0.05$ was considered to indicate a statistically significant 
Table I. Characteristics of the study population.

\begin{tabular}{|c|c|c|c|c|}
\hline Characteristics & Normal, $n=227$ & $\mathrm{CHB}, \mathrm{n}=242$ & $\mathrm{LC}, \mathrm{n}=215$ & HCC, $n=202$ \\
\hline Age, years & $51.2 \pm 14.23$ & $49.8 \pm 13.54$ & $50.5 \pm 15.14$ & $50.7 \pm 13.96$ \\
\hline \multicolumn{5}{|l|}{ Sex, n (\%) } \\
\hline Male & $166(73.1)$ & $180(74.4)$ & $162(75.3)$ & $151(74.8)$ \\
\hline Female & $61(26.9)$ & $62(25.6)$ & $53(24.7)$ & $51(25.2)$ \\
\hline \multicolumn{5}{|c|}{ HBV infection, n (\%) } \\
\hline Yes & $0(0)$ & $242(100.0)$ & $149(69.3)$ & $151(74.8)$ \\
\hline No & $227(100.0)$ & $0(0)$ & $66(30.7)$ & $51(25.2)$ \\
\hline \multicolumn{5}{|c|}{$\mathrm{HCV}$ infection, n (\%) } \\
\hline Yes & $0(0)$ & $0(0)$ & $9(4.2)$ & $11(5.4)$ \\
\hline No & $227(100.0)$ & $242(100.0)$ & $206(95.8)$ & $191(94.6)$ \\
\hline \multicolumn{5}{|c|}{ Alcoholic liver disease, n (\%) } \\
\hline Yes & $0(0)$ & $0(0)$ & $62(28.8)$ & $51(25.2)$ \\
\hline No & $227(100.0)$ & $242(100.0)$ & $153(71.2)$ & $151(74.8)$ \\
\hline
\end{tabular}

HBV, hepatitis B virus; HCV, hepatitis C virus; HCC, hepatocellular carcinoma; CHB, chronic hepatitis B; LC, liver cirrhosis.

Table II. Macrophage migration inhibitory factor gene polymorphisms in 202 patients with HCC and 227 normal volunteers.

\begin{tabular}{|c|c|c|c|c|c|}
\hline SNPs & Genotype & $\mathrm{HCC}, \mathrm{n}(\%)$ & Normal, n (\%) & $\chi^{2}$ & P-value \\
\hline \multirow[t]{5}{*}{ rs755622 } & GG & $109(54.0)$ & $158(69.6)$ & 13.167 & 0.001 \\
\hline & $\mathrm{GC}$ & $76(37.6)$ & $62(27.3)$ & & \\
\hline & $\mathrm{CC}$ & $17 \quad(8.4)$ & $7 \quad(3.1)$ & & \\
\hline & Allele G & $294(72.8)$ & $378(83.3)$ & 13.848 & $<0.001$ \\
\hline & Allele C & $110(27.2)$ & $76(16.7)$ & & \\
\hline \multirow[t]{5}{*}{ rs1007888 } & $\mathrm{AA}$ & $48(23.8)$ & $66(29.1)$ & 1.685 & 0.431 \\
\hline & $\mathrm{AG}$ & $109(54.0)$ & $117(51.5)$ & & \\
\hline & GG & $45(22.2)$ & $44(19.4)$ & & \\
\hline & Allele A & $205(50.7)$ & $249(54.8)$ & 1.445 & 0.229 \\
\hline & Allele G & 199 (49.3) & $205(45.2)$ & & \\
\hline \multirow[t]{5}{*}{ rs2096525 } & $\mathrm{CC}$ & $145(71.8)$ & $144(63.4)$ & 3.391 & 0.183 \\
\hline & $\mathrm{CT}$ & $49(24.2)$ & $71(31.3)$ & & \\
\hline & $\mathrm{TT}$ & $8 \quad(4.0)$ & $12(5.3)$ & & \\
\hline & Allele C & $339(84.0)$ & $359(79.1)$ & 3.296 & 0.069 \\
\hline & Allele T & $65(16.0)$ & 95 (20.9) & & \\
\hline
\end{tabular}

SNP, single nucleotide polymorphisms; HCC, hepatocellular carcinoma.

difference. SPSS version 20.0 (IBM Corp) was used to perform all statistical analyses.

\section{Results}

Characteristics of the study population. The characteristics of the study population are shown in Table I. The four groups of subjects are balanced and comparable in terms of age and sex. The infection rate of hepatitis B virus in the LC group was $69.3 \%$, while that in the HCC group was $74.8 \%$. The infection rate of hepatitis $\mathrm{C}$ virus in the $\mathrm{LC}$ group was $4.2 \%$, while the infection rate of hepatitis $\mathrm{C}$ virus in the HCC group was $5.4 \%$.
Alcoholic liver disease accounted for $28.8 \%$ in the LC group and $25.2 \%$ in the HCC group.

Association of MIF polymorphisms with the risk of $C H B, L C$ and $H C C$. The genotype distributions of the two polymorphisms among patients with HCC, CHB and LC, as well as healthy volunteers, were all consistent with Hardy-Weinberg equilibrium (all $\mathrm{P}>0.05$ ).

After adjusting for age and sex, it was observed that the MIF gene rs755622polymorphism was associated with an increased susceptibility to HCC $(\mathrm{P}=0.001)$, and that allele $\mathrm{C}$ may be risk factors for HCC $(\mathrm{P}<0.001$; Table II). However, 
Table III. Macrophage migration inhibitory factor gene polymorphisms in 242 patients with CHB and 227 normal volunteers.

\begin{tabular}{|c|c|c|c|c|c|}
\hline SNPs & Genotype & CHB, n (\%) & Normal, n (\%) & $\chi^{2}$ & P-value \\
\hline \multirow[t]{5}{*}{ rs755622 } & GG & $161(66.5)$ & 158 (69.6) & 0.688 & 0.709 \\
\hline & GC & $71(29.3)$ & $62(27.3)$ & & \\
\hline & $\mathrm{CC}$ & $10 \quad(4.2)$ & $7 \quad(3.1)$ & & \\
\hline & Allele G & $393(81.2)$ & $378(83.3)$ & 0.680 & 0.409 \\
\hline & Allele C & $91(18.8)$ & $76(16.7)$ & & \\
\hline \multirow[t]{5}{*}{ rs1007888 } & AA & 57 (23.6) & $66(29.1)$ & 3.389 & 0.184 \\
\hline & $\mathrm{AG}$ & $123(50.8)$ & $117(51.5)$ & & \\
\hline & GG & $62(25.6)$ & $44(19.4)$ & & \\
\hline & Allele A & $237(49.0)$ & $249(54.8)$ & 3.243 & 0.072 \\
\hline & Allele G & $247(51.0)$ & 205 (45.2) & & \\
\hline \multirow[t]{5}{*}{ rs2096525 } & $\mathrm{CC}$ & $167(69.0)$ & $144(63.4)$ & 1.669 & 0.434 \\
\hline & $\mathrm{CT}$ & 65 (26.9) & $71(31.3)$ & & \\
\hline & TT & $10 \quad(4.1)$ & $12 \quad(5.3)$ & & \\
\hline & Allele C & $399(82.4)$ & $359(79.1)$ & 1.709 & 0.191 \\
\hline & Allele T & 85 (17.6) & 95 (20.9) & & \\
\hline
\end{tabular}

SNP, single nucleotide polymorphisms; CHB, chronic hepatitis B.

Table IV. Macrophage migration inhibitory factor gene polymorphisms in 215 patients with liver cirrhosis and 227 normal volunteers.

\begin{tabular}{|c|c|c|c|c|c|}
\hline SNPs & Genotype & $\mathrm{LC}$ & Normal & $\chi^{2}$ & $\mathrm{P}$-value \\
\hline \multirow[t]{5}{*}{ rs755622 } & GG & 139 (64.7) & 158 (69.6) & 1.334 & 0.513 \\
\hline & $\mathrm{GC}$ & $67(31.2)$ & $62(27.3)$ & & \\
\hline & $\mathrm{CC}$ & $9 \quad(4.2)$ & $7 \quad(3.1)$ & & \\
\hline & Allele G & $345(80.2)$ & $378(83.3)$ & 1.359 & 0.244 \\
\hline & Allele C & $85(19.8)$ & $76(16.7)$ & & \\
\hline \multirow[t]{5}{*}{ rs1007888 } & $\mathrm{AA}$ & $52(24.2)$ & $66(29.1)$ & 1.962 & 0.375 \\
\hline & $\mathrm{AG}$ & $112(52.1)$ & $117(51.5)$ & & \\
\hline & GG & $51(23.7)$ & $44(19.4)$ & & \\
\hline & Allele A & $216(50.2)$ & $249(54.8)$ & 1.885 & 0.170 \\
\hline & Allele G & $214(49.8)$ & $205(45.2)$ & & \\
\hline \multirow[t]{5}{*}{ rs2096525 } & $\mathrm{CC}$ & $152(70.7)$ & $144(63.4)$ & 2.633 & 0.268 \\
\hline & $\mathrm{CT}$ & $54(25.1)$ & $71(31.3)$ & & \\
\hline & TT & $9 \quad(4.2)$ & $12 \quad(5.3)$ & & \\
\hline & Allele C & $358(83.3)$ & $359(79.1)$ & 2.519 & 0.112 \\
\hline & Allele T & $72(16.7)$ & $95(20.9)$ & & \\
\hline
\end{tabular}

SNP, single nucleotide polymorphisms; LC, liver cirrhosis.

the MIF rs1007888 and rs2096525 polymorphisms were not associated with susceptibility to HCC ( $\mathrm{P}>0.05$; Table II). Moreover, MIF rs755622, rs1007888 and rs2096525 polymorphisms were not associated with susceptibility to CHB or LC (Tables III and IV).

Association of MIF rs755622 polymorphism with clinical parameters in HCC. There was a significant association between the MIF rs755622 polymorphism and TNM stage, lymph node metastasis and distant metastasis of HCC (all $\mathrm{P}<0.05$; Table $\mathrm{V}$ ). However, no association was found between the MIF rs755622 polymorphism and AFP levels or imaging classification in patients with HCC (Table V).

MIF rs755622 polymorphism and prognosis. Next, survival analysis for patients in the HCC group was performed. At the end of the follow-up, survival information was available from 163 patients (genotype distribution: $88 \mathrm{GG}, 61 \mathrm{GC}$ 
Table V. Macrophage migration inhibitory factor rs755622 polymorphism in relation to clinical parameters in patients with hepatocellular carcinoma.

\begin{tabular}{|c|c|c|c|c|c|}
\hline \multirow[b]{2}{*}{ Clinical variable } & \multicolumn{3}{|c|}{ Genotype, n (\%) } & \multirow[b]{2}{*}{$\chi^{2}$} & \multirow[b]{2}{*}{ P-value } \\
\hline & GG & GC & $\mathrm{CC}$ & & \\
\hline AFP, ng/ml & & & & 0.669 & 0.716 \\
\hline$>400$ & $75(55.1)$ & $51(37.5)$ & $10(7.4)$ & & \\
\hline$<400$ & $34(51.5)$ & $25(37.9)$ & 7 (10.6) & & \\
\hline Imaging classification & & & & 0.391 & 0.822 \\
\hline Lump type & $72(54.5)$ & 48 (36.4) & $12(9.1)$ & & \\
\hline Nodular type +diffuse type & $37(52.9)$ & $28(40.0)$ & $5(7.1)$ & & \\
\hline TNM stage & & & & 11.663 & 0.003 \\
\hline $\mathrm{I}+\mathrm{II}$ & $53(68.8)$ & $21(27.3)$ & $3(3.9)$ & & \\
\hline $\mathrm{III}+\mathrm{IV}$ & $56(44.8)$ & $55(44.0)$ & $14(11.2)$ & & \\
\hline Lymph node metastasis & & & & 11.054 & 0.004 \\
\hline Yes & $81(48.8)$ & $68(41.0)$ & $17(10.2)$ & & \\
\hline No & $28(77.8)$ & $8(22.2)$ & $0(0)$ & & \\
\hline Distant metastasis & & & & 12.017 & 0.002 \\
\hline Yes & $15(34.1)$ & $21(47.7)$ & $8(18.2)$ & & \\
\hline No & $94(59.5)$ & $55(34.8)$ & $9(5.7)$ & & \\
\hline
\end{tabular}

AFP, $\alpha$-fetoprotein; TNM, Tumor-Node-Metastasis.

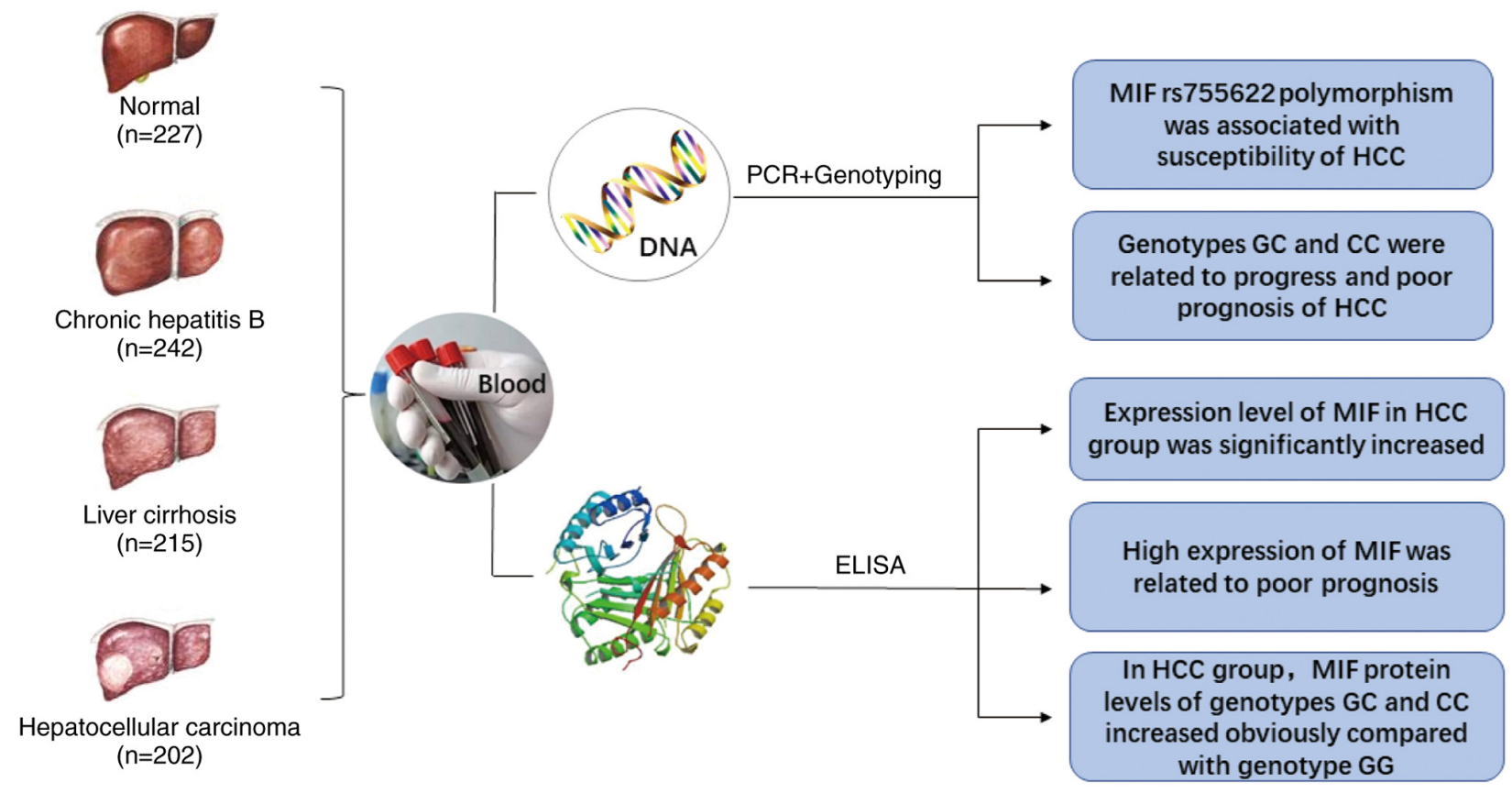

Figure 1. MIF gene polymorphism increased peripheral blood expression levels, contributing to increased susceptibility and poor prognosis in HCC. MIF, macrophage migration inhibitory factor; HCC, hepatocellular carcinoma.

and $14 \mathrm{CC}$ ). The dropout rate was $19.3 \%$. The reason for the dropout rate of $19.3 \%$ was data not being available. Allele C of MIF rs755622 was significantly related to the susceptibility of HCC $(\mathrm{P}<0.001)$; in addition, the proportions of GC and CC genotypes in the HCC group were 37.6 and $8.4 \%$, respectively, which were significantly higher compared with the proportions of GC and CC genotypes in the normal group (27.3 and 3.1\%). Hence, GC and CC genotypes were risk factors for the occurrence of $\mathrm{HCC}$ and were analyzed together. According to a Kaplan-Meier analysis, the overall survival in patients with the GC and CC genotypes of MIF rs755622 was much shorter compared with those with the GG genotype (median overall 


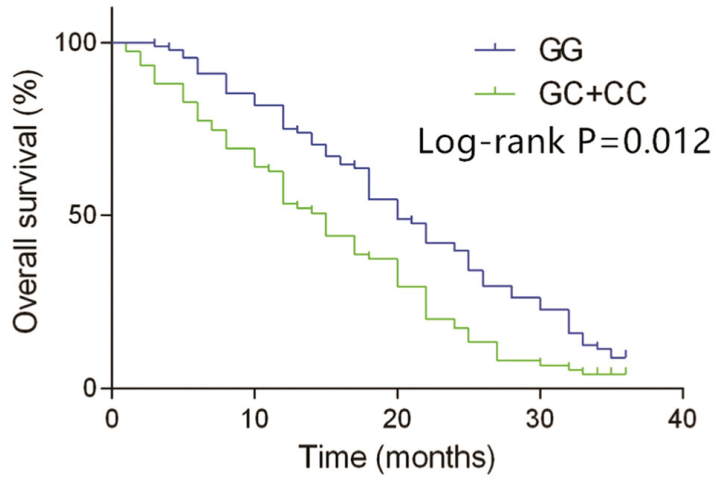

Figure 2. Kaplan-Meier survival curves for patients with different genotypes of macrophage migration inhibitory factor rs755622. Overall survival of patients with the GC and CC genotypes was much shorter compared with those with GG genotype (log-rank $\mathrm{P}=0.012)$.

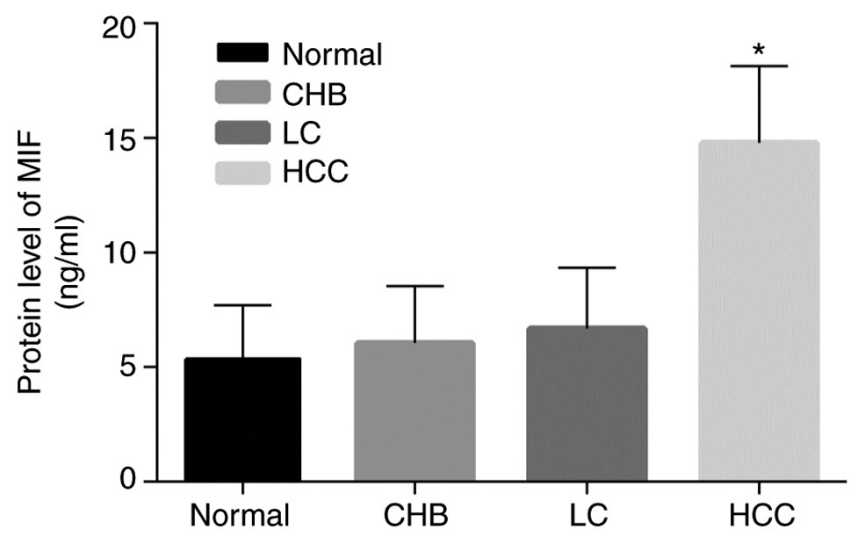

Figure 3. Protein expression of MIF in each group. Bar graph represents the mean protein expression levels of MIF detected by ELISA. ${ }^{*} \mathrm{P}<0.05$ compared with normal, $\mathrm{CHB}$ and LC groups. MIF, macrophage migration inhibitory factor; $\mathrm{HCC}$, hepatocellular carcinoma; $\mathrm{CHB}$, chronic hepatitis $\mathrm{B}$; LC, liver cirrhosis.

survival time, 15.7 months vs. 20.2 months; $\log$-rank $\mathrm{P}=0.012$; Fig. 2). These results indicated that the GC and $\mathrm{CC}$ genotypes may be an indicator of poor prognosis in patients with HCC.

Expression levels of MIF in patients with $C H B, L C$ and $H C C$. ELISA showed that, the expression of MIF in the HCC group was significantly increased compared with the normal, CHB and LC groups; however, the expression levels of MIF in the CHB and LC groups were not remarkably increased compared with the normal group ( $\mathrm{P}>0.05$; Fig. 3). These data revealed that MIF in peripheral blood may be involved in the pathogenesis of HCC.

MIF expression level and prognosis. With a median concentration of MIF in peripheral blood $(14.80 \mathrm{ng} / \mathrm{ml})$ as the cut-off point, 163 patients with $\mathrm{HCC}$ with survival information were divided into the high expression group $(\geq 14.80 \mathrm{ng} / \mathrm{ml}, \mathrm{n}=81)$ and the low expression group $(<14.80 \mathrm{ng} / \mathrm{ml}, \mathrm{n}=82)$. According to Kaplan-Meier analysis, the overall survival time in patients with the high expression of MIF was much shorter compared with those with the low expression of MIF (median overall survival time, 15.5 months vs. 20.0 months; $\log$-rank $\mathrm{P}=0.021$;

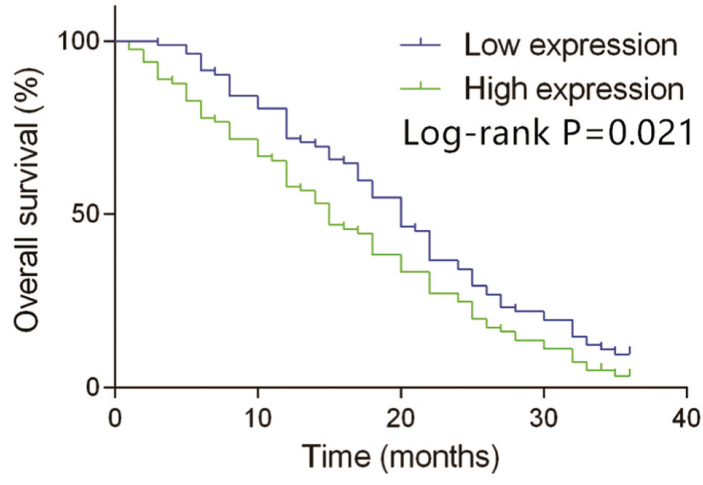

Figure 4. Kaplan-Meier survival curves for patients with low or high expression levels of MIF. Overall survival of patients with high expression level of MIF was much shorter compared with those with low expression levels (log-rank $\mathrm{P}=0.021)$. MIF, macrophage migration inhibitory factor.

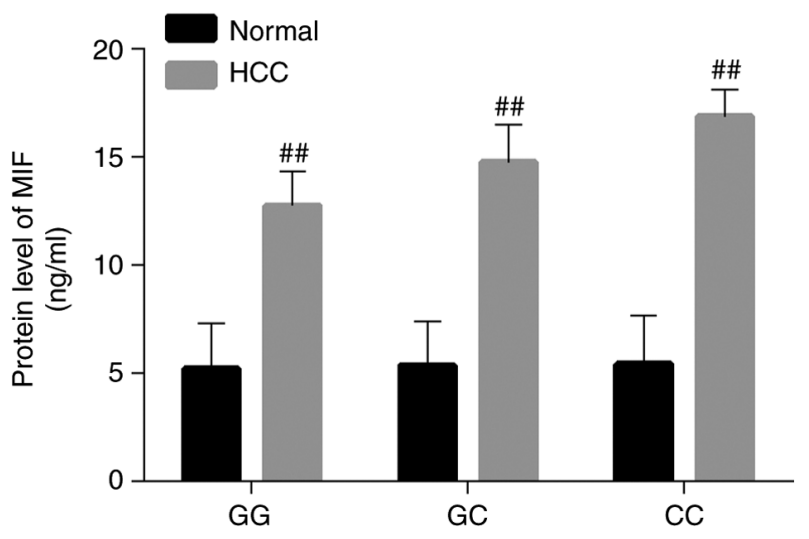

Figure 5. MIF protein level of different genotypes in normal and HCC group. ${ }^{\# \#} \mathrm{P}<0.01$ compared with the same genotype in the normal group. HCC, hepatocellular carcinoma; MIF, macrophage migration inhibitory factor.

Fig. 4). These data suggested that the high expression of MIF may be an indicator of poor prognosis.

Expression levels of MIF in patients with HCC patients with different genotypes. The MIF protein levels for all genotypes in the HCC group increased significantly compared with the normal group $(\mathrm{P}<0.01 ;$ Fig. 5$)$. In the HCC group, the MIF protein levels for the genotypes $\mathrm{GC}$ and $\mathrm{CC}$ were significantly increased compared with the genotype GG, especially for genotype $\mathrm{CC}(\mathrm{P}<0.05$; Fig. 6). Disease status and genotype are synergistic (Fig. 7). These results confirmed that genotypes GC and CC of MIF rs755622 may contribute to its expression in peripheral blood.

\section{Discussion}

MIF, a protein with a molecular weight of $12.5 \mathrm{kDa}$, is composed of 115 amino acids, and is an open-ended hollow structure consisting of three monomers (each containing two anti-parallel $\alpha$ helices and six $\beta$ sheets) (13). The homology of the MIF gene in all mammals is $\sim 90 \%$, suggesting that the MIF protein may have important biological functions (14). The human MIF gene contains two introns and three exons, and 


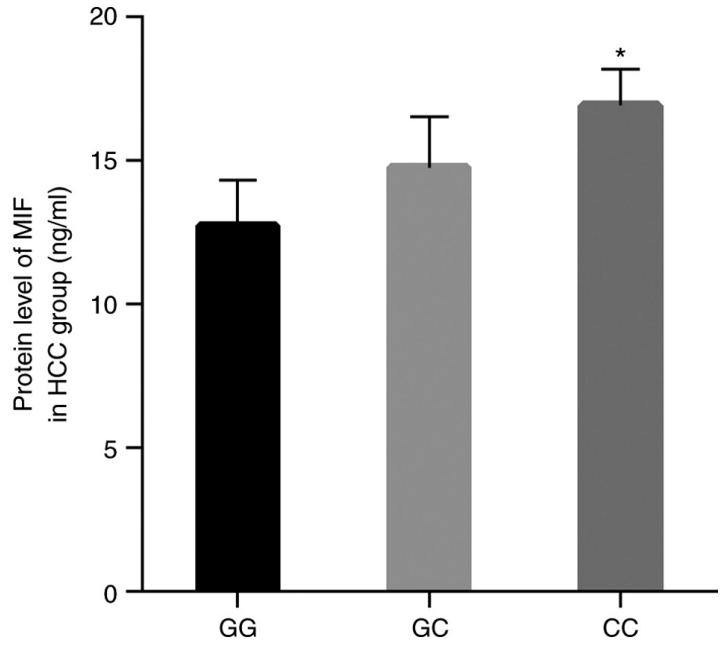

Figure 6. MIF protein level of different genotypes in HCC group. ${ }^{*} \mathrm{P}<0.05$ compared with GG genotype. HCC, hepatocellular carcinoma; MIF, macrophage migration inhibitory factor.

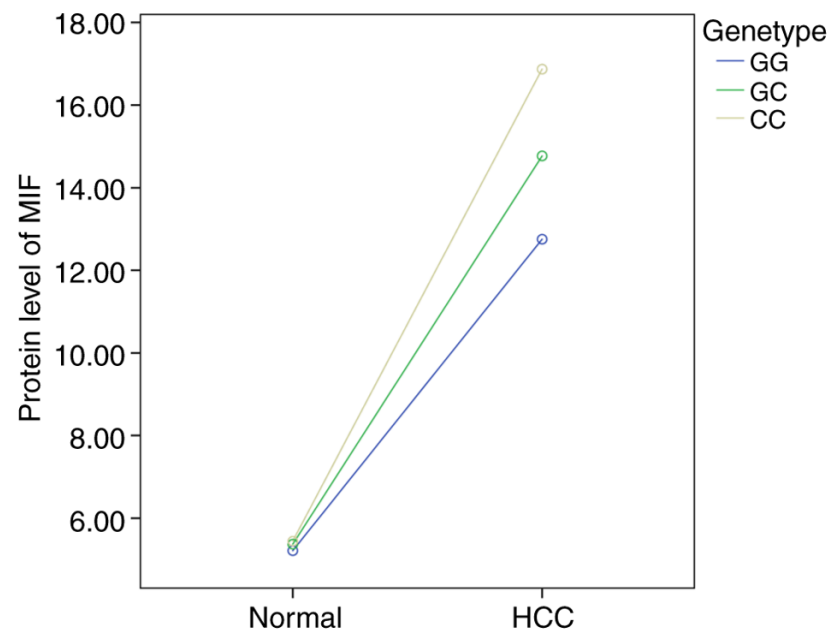

Figure 7. Effect of different disease states and genotypes on the expression level of MIF. HCC, hepatocellular carcinoma; MIF, macrophage migration inhibitory factor.

the mRNA is $\sim 0.8 \mathrm{~kb}$ in length (6). MIF is widely expressed in various tissues and cells, such as anterior pituitary cells, activated $\mathrm{T}$ lymphocytes, mononuclear macrophages, the liver, kidneys and spleen (14). In the past, MIF was considered an inflammatory mediator (15), but recent studies (16-18) have demonstrated that MIF is closely related to the occurrence and progression of tumors.

A number of studies have demonstrated that MIF plays a crucial role in the pathogenesis of HCC through multiple mechanisms. Firstly, MIF promotes the formation of blood vessels in HCC. Macrophages usually accumulate in the interstitial tissue adjacent to the infiltrating area of the tumor. The interaction of tumor cells with macrophages results in the production of extracellular matrix-degrading enzymes and promotes tumor angiogenesis $(5,19)$. Secondly, MIF promotes the proliferation of HCC cells. MIF can upregulate the extracellular signal-regulated kinase (ERK) and mitogen-activated protein kinase (MAPK) through signaling pathways. Signals are transmitted to the nucleus after the phosphorylation of ERK/MAPK, thereby causing the proliferation and differentiation of tumor cells $(20,21)$. Thirdly, MIF promotes the invasion and migration of HCC cells. MIF increases the adhesion and migration of cancer cells through the Rho signaling transduction pathway, which can indirectly promote the invasion and migration of cancer cells by inducing the production of MMP-9 and IL-8 (22,23). Fourthly, MIF affects P53; the P53 gene is one of the most important genes that determine tumor occurrence in the human body, such as esophagus cancer, breast cancer, hepatocellular carcinoma and so on (24-26). MIF leads to tumorigenesis and progression by affecting the function of P53 or cooperating with functional mutant p53 (27,28).

The present study reported that the MIF rs755622 polymorphism is associated with susceptibility and metastasis of HCC, which is an indicator of poor prognosis. Ramireddy et al (29) found that the presence of the MIF rs755662 polymorphism was associated with susceptibility, patient age and TNM stages of colorectal cancer in the Taiwanese population. A previous study (30) in Chinese women showed that the MIF rs755622 polymorphism increases breast cancer susceptibility, and that individuals with the GC and CC genotypes have a significantly increased risk. The study by Ding et al (31) suggested that the MIF rs755662 polymorphism may be associated with an increased incidence of prostate cancer and may be associated with higher Gleason scores, higher clinical stages and overexpression of serological prostate-specific antigen. A previous meta-analysis (32) included 15 studies in Asian and Caucasian populations and indicated that the MIF rs755662 polymorphism may be an independent risk factor for gastrointestinal cancer and hematological malignancy susceptibility. Yuan et al (33) reported that MIF gene polymorphisms may be associated with the surgical prognosis of HCC, such as differentiation grade, TNM stage, survival rate, recurrence, metastasis and average survival time. These findings are consistent with our results.

MIF is highly expressed in a variety of tumors, precancerous lesions and tumor metastasis tissue, especially in HCC (34). Wang et al (35) found that the expression levels of MIF in the serum from patients with HCC are higher compared with the levels from healthy volunteers, and the expression levels of MIF in tissues are also higher compared with those in the adjacent non-tumor liver tissues. Zhao et al (36) reported that the intratumoral MIF expression level of HCC was positively correlated with plasma MIF levels, and that plasma MIF had an improved diagnostic value compared with AFP. Furthermore, plasma MIF levels demonstrated a significant association with overall and tumor-free survival time in patients with HCC. Han and Zhang (37) deemed that MIF is important for the progression and prognosis of HCC, which can be used as a biomarker for HCC diagnosis. The present study showed that MIF expression levels in the peripheral blood from patients with HCC were significantly higher compared with those from patients with $\mathrm{CHB}$ and LC or healthy volunteers, and that high levels of MIF in peripheral blood from patients with HCC may be an indicator of poor prognosis, and the results of the present study were consistent with the aforementioned previous studies.

In addition, the present study also reported that MIF rs755622 polymorphism contribute to MIF expression. The 
rs755622 polymorphism is located in the promoter region of the MIF gene. Changes in this locus, from $\mathrm{G}$ to $\mathrm{C}$, affect the transcription and translation of the MIF gene, thereby upregulating the expression levels of MIF and ultimately determining the susceptibility and prognosis of multiple diseases, such as arthritis, autoimmune disease and cancer (38). MIF is not just only about the gene polymorphism, it is also about the state of the disease. It is considered that the genetic polymorphism and disease state jointly determine the expression of MIF, and the latter may be the main factor, and the former may be the secondary factor. At present, $\mathrm{HCC}$ is still a refractory disease, but MIF is expected to improve HCC therapies through correlation with predictive/prognostic factors in the future (39). MIF may be a potential diagnostic/prognostic indicator for HCC.

Most cases of HCC are based on chronic viral hepatitis and cirrhosis (1); therefore, the present study used CHB and LC as controls. The results showed that the MIF rs755622 polymorphism is only associated with HCC but not with CHB and LC. Nonetheless, conflicting data have previously been reported, showing that the MIF rs755622 polymorphism was associated with $\mathrm{CHB}$ and $\mathrm{HBV}$-induced liver cirrhosis (40). The discrepancy may lie in the small sample size in the study by Zhang et al (40) and ethnic or regional differences in genetic polymorphisms.

However, there were some limitations of the present study. In the present study, the sample size was small, and the study was conducted only in the Chinese Han population. In addition, the present study only detected the expression level of MIF in the peripheral blood of subjects and did not detect the expression level of MIF in the liver tissue. Hence, the results of the present study have yet to be further validated in studies with larger cohorts and other ethnic groups, as well as more in-depth experimental tissue and cellular studies.

In summary, the MIF rs755622 polymorphism is associated with susceptibility to $\mathrm{HCC}$ in the Chinese Han population, and is related to metastasis or poor prognosis of HCC, which may be due to the MIF rs755622 polymorphism upregulating its expression in peripheral blood.

\section{Acknowledgements}

Not applicable.

\section{Funding}

This study was supported by the National Natural Sciences Funds of China (No.81860104 and 81860369).

\section{Availability of data and materials}

The datasets used and/or analyzed during the current study are available from the corresponding author on reasonable request.

\section{Authors' contributions}

LFQ and XPL conceived of the study. JMQ, QEZ, JQZ and CQY performed the experiments. LFQ analyzed the data and drafted the manuscript. LFQ, QEZ and JQZ ensure the authenticity of the raw data. All authors read and approved the final manuscript.

\section{Ethics approval and consent to participate}

The present study was approved by the Ethics Committee of The First Affiliated Hospital of Guangxi Medical University (Nanning, China). The patients provided written informed consent for the use of their data.

\section{Patient consent for publication}

Not applicable.

\section{Competing interests}

The authors declare that they have no competing interests.

\section{References}

1. Kulik L and El-Serag HB: Epidemiology and management of hepatocellular carcinoma. Gastroenterology 156: 477-491.e1, 2019.

2. Chen W, Zheng R, Baade PD, Zhang S, Zeng H, Bray F, Jemal A, $\mathrm{Yu}$ XQ and He J: Cancer statistics in China, 2015. CA Cancer J Clin 66: 115-132, 2016.

3. Pal LR and Moult J: Genetic basis of common human disease: Insight into the role of missense SNPs from genome-wide association studies. J Mol Biol 427: 2271-2289, 2015.

4. Nie S, Wang H and Wang X: Research progress on polymorphism of susceptibility genes in hepatocellular carcinoma. Int J Genet 41: 512-517, 2018.

5. Nobre CC, de Araújo JM, Fernandes TA, Cobucci RN, Lanza DC, Andrade VS and Fernandes JV: Macrophage migration inhibitory factor (MIF): Biological activities and relation with cancer. Pathol Oncol Res 23: 235-244, 2017.

6. Grieb G, Merk M, Bernhagen J and Bucala R: Macrophage migration inhibitory factor (MIF): A promising biomarker. Drug News Perspect 23: 257-264, 2010.

7. Illescas O,Gomez-Verjan JC, Garcia-Velazquez L, Govezensky T and Rodriguez-Sosa M: Macrophage migration inhibitory factor-173 G/C polymorphism: A global meta-analysis across the disease spectrum. Front Genet 9: 55, 2018.

8. Fukui H, Saito H, Ueno Y, Uto H, Obara K, Sakaida I, Shibuya A, Seike M, Nagoshi S, Segawa M, et al: Evidence-based clinical practice guidelines for liver cirrhosis 2015. J Gastroenterol 51: 629-650, 2016.

9. Hou J, Wang G, Wang F, Cheng J, Ren H, Zhuang H, Sun J, Li L, Li J, Meng Q, et al: Guideline of prevention and treatment for chronic hepatitis B (2015 Update). J Clin Transl Hepatol 5: 297-318, 2017.

10. Zhou J, Sun H, Wang Z, Cong W, Wang J, Zeng M, Zhou W, Bie P, Liu L, Wen T, et al: Guidelines for the diagnosis and treatment of hepatocellular carcinoma (2019 edition). Liver Cancer 9: 682-720, 2020.

11. Forner A, Reig ME, de Lope CR and Bruix J: Current strategy for staging and treatment: The BCLC update and future prospects. Semin Liver Dis 30: 61-74, 2010.

12. Ayuso C, Rimola J, Vilana R, Burrel M, Darnell A, García-Criado Á, Bianchi L, Belmonte E, Caparroz C, Barrufet $\mathrm{M}$, et al: Diagnosis and staging of hepatocellular carcinoma (HCC): Current guidelines. Eur J Radiol 101: 72-81, 2018.

13. Meza-Romero R, Benedek G, Leng L, Bucala R and Vandenbark AA: Predicted structure of MIF/CD74 and RTL1000/CD74 complexes. Metab Brain Dis 31: 249-255, 2016.

14. Jankauskas SS, Wong DWL, Bucala R, Djudjaj S and Boor P: Evolving complexity of MIF signaling. Cell Signal 57: 76-88, 2019.

15. Conroy H. Mawhinney L and Donnelly SC: Inflammation and cancer: Macrophage migration inhibitory factor (MIF)-the potential missing link. QJM 103: 831-836, 2010.

16. Jäger B, Klatt D, Plappert L, Golpon H, Lienenklaus S, Barbosa PD, Schambach A and Prasse A: CXCR4/MIF axis amplifies tumor growth and epithelial-mesenchymal interaction in non-small cell lung cancer. Cell Signal 73: 109672, 2020.

17. Guda MR, Rashid MA, Asuthkar S, Jalasutram A, Caniglia JL, Tsung AJ and Velpula KK: Pleiotropic role of macrophage migration inhibitory factor in cancer. Am J Cancer Res 9: 2760-2773, 2019. 
18. Penticuff JC, Woolbright BL, Sielecki TM, Weir SJ and Taylor JA: MIF family proteins in genitourinary cancer: Tumorigenic roles and therapeutic potential. Nat Rev Urol 16: 318-328, 2019.

19. Hira E, Ono T, Dhar DK, El-Assal ON, Hishikawa Y, Yamanoi A and Nagasue N: Overexpression of macrophage migration inhibitory factor induces angiogenesis and deteriorates prognosis after radical resection for hepatocellular carcinoma. Cancer 103: 588-598, 2005.

20. Li QT, Feng YM, Ke ZH, Qiu MJ and Xiong ZF: KCNN4 promotes invasion and metastasis through the MAPK/ERK pathway in hepatocellular carcinoma. J Investig Med 68: 68-74, 2019.

21. Songlin M, Fei X, Long Y and Yang L: The effect of miRNA-451 on the proliferation and invasion capacity of human hepatocellular carcinoma cell lines via its regulation on COX-2 and other cytokines. Oncol Progress 16: 690-693, 2018.

22. Sun B, Nishihira J, Yoshiki T, Kondo M, Sato Y, Sasaki F and Todo S: Macrophage migration inhibitory factor promotes tumor invasion and metastasis via the Rho-dependent pathway. Clin Cancer Res 11: 1050-1058, 2005.

23. Pei XJ, Wu TT, Li B, Tian XY, Li Z and Yang QX: Increased expression of macrophage migration inhibitory factor and DJ-1 contribute to cell invasion and metastasis of nasopharyngeal carcinoma. Int J Med Sci 11: 106-115, 2014

24. Liu J, Zhang C, Hu W and Feng Z: Tumor suppressor p53 and its mutants in cancer metabolism. Cancer Lett 356: 197-203, 2015.

25. Mathumai K: Treating p53 mutant aggregation-associated cancer. Cancers 10: 154, 2018

26. Ubby I, Krueger C, Rosato R, Qian W, Chang J and Sabapathy K: Cancer therapeutic targeting using mutant-p53-specific siRNAs. Oncogene 38: 3415-3427, 2019.

27. Fukaya R, Ohta S, Yaguchi T, Matsuzaki Y, Sugihara E, Okano H, Saya H, Kawakami Y, Kawase T, Yoshida K and Toda M: MIF maintains the tumorigenic capacity of brain tumor-initiating cells by directly inhibiting p53. Cancer Res 76: 2813-2823, 2016.

28. Kong F, Xuan D, Kong X, Du Y, Li L, Zhu H, Wang Y, Xie D, Guha S, Li Z, et al: ZFPM2-AS1, a Novel lncRNA, attenuates the p53 pathway and promotes gastric carcinogenesis by stabilizing MIF. Oncogene 37: 5982-5996, 2018.

29. Ramireddy L, Chen WT, Peng CT, Hu RM, Ke TW, Chiang HC, Chang SC, Tsai FJ and Lo WY: Association between genetic polymorphism of the MIF gene and colorectal cancer in Taiwan. J Clin Lab Anal 29: 268-274, 2015.

30. Lin S, Wang M, Liu X, Zhu W, Guo Y, Dai Z, Yang P, Tian T, Dai C, Zheng Y, et al: Association of genetic polymorphisms in MIF with breast cancer risk in Chinese women. Clin Exp Med 17: 395-401, 2017.
31. Ding GX, Zhou SQ, Xu Z, Feng NH, Song NH, Wang XJ, Yang J, Zhang W, Wu HF and Hua LX: The association between MIF-173 $\mathrm{G}>\mathrm{C}$ polymorphism and prostate cancer in southern Chinese. J Surg Oncol 100: 106-110, 2009.

32. Xiang T, Bing Z, Tong Q, Liu S, Peng S, Yang X and Fan H: The MIF-173G/C gene polymorphism increase gastrointestinal cancer and hematological malignancy risk: Evidence from a meta-analysis and FPRP test. Int J Clin Exp Med 8: 15949-15957, 2015.

33. Yuan T, Tang C, Chen M, Deng S and Chen P: Influence of the human MIF promoter polymorphism on hepatocellular carcinoma prognosis. Genet Mol Res 12: 6629-6635, 2013.

34. O'Reilly C, Doroudian M, Mawhinney L and Donnelly SC: Targeting MIF in cancer: Therapeutic strategies, current developments, and future opportunities. Med Res Rev 36: 440-460, 2016.

35. Wang D, Luo L, Chen W, Chen LZ, Zeng WT, Li W and Huang XH: Significance of the vascular endothelial growth factor and the macrophage migration inhibitory factor in the progression of hepatocellular carcinoma. Oncol Rep 31: 1199-1204, 2014.

36. Zhao YM, Wang L, Dai Z, Wang DD, Hei ZY, Zhang N, Fu XT, Wang XL, Zhang SC, Qin LX, et al: Validity of plasma macrophage migration inhibitory factor for diagnosis and prognosis of hepatocellular carcinoma. Int J Cancer 129: 2463-2472, 2011.

37. Han Y and Zhang C: Macrophage migration inhibitory factor plays a pivotal role in hepatocellular carcinoma and may be a noninvasive imaging target. Medical Hypotheses 75: 530-532, 2010.

38. Oscar I, Gomez-Verjan JC, Lizbeth GV, Tzipe G and Miriam RS: Macrophage migration inhibitory factor- $173 \mathrm{G} / \mathrm{C}$ polymorphism: A global meta-analysis across the disease spectrum. Front Genet 9: 55, 2018.

39. Gnoni A, Santini D, Scartozzi M, Russo A, Licchetta A, Palmieri V, Lupo L, Faloppi L, Palasciano G, Memeo V, et al: Hepatocellular carcinoma treatment over sorafenib: Epigenetics, microRNAs and microenvironment. Is there a light at the end of the tunnel? Expert Opin Ther Targets 19: 1623-1635, 2015.

40. Zhang K, Pan X, Shu X, Cao H, Chen L, Zou Y, Deng H, Li G and $\mathrm{Xu}$ Q: Relationship between MIF-173 G/C polymorphism and susceptibility to chronic hepatitis B and HBV-induced liver cirrhosis. Cell Immunol 282: 113-116, 2013.

This work is licensed under a Creative Commons Attribution-NonCommercial-NoDerivatives 4.0 International (CC BY-NC-ND 4.0) License. 